\title{
Chapter 4 \\ Public Engagement in the Governance of Science and Technology
}

\author{
Yandong Zhao, Camilo Fautz, Leonhard Hennen, \\ Krishna Ravi Srinivas and Qiang Li
}

\subsection{Introduction}

In contemporary societies 'public engagement' or 'public participation' is becoming an increasingly popular means of approaching certain highly awkward issues such as the management of risks or the development and socially sound implementation of emerging technologies. There are many reasons, practical and normative, for policymakers to involve lay people in policy-making (e.g. Fiorino 1990; National Research Council 1996). In the field of emerging technologies scientific uncertainties frequently exist in combination with a plurality of value-based perspectives. In those cases decisions may be influenced to a significant extent by the values of the experts involved, who cannot claim that their moral sentiments have a higher validity than those of the public.

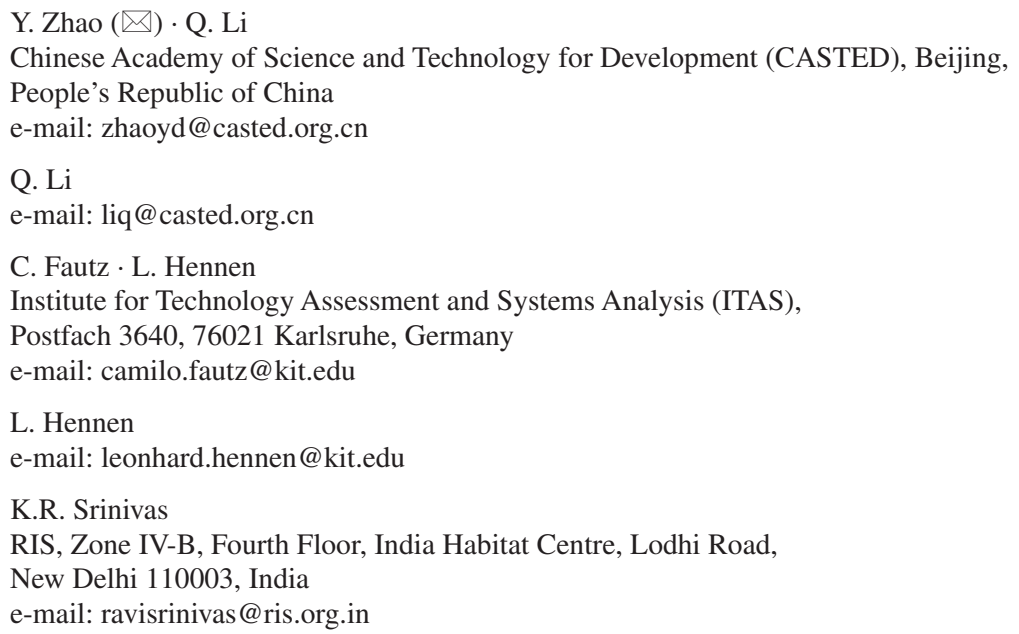


Aside from ethical and normative reflections, decisions made without public support tend to provoke a loss of empirical legitimacy that may be expressed in confrontation, disruption and public distrust. Emerging technologies such as food technologies, nanotechnologies and synthetic biology are increasingly regarded as political issues due to their potentially immense impact on society associated with controversies about risk and benefits and ethical disputes about human dignity, the common good and questions of responsible research. Hence the fact that many questions, such as the setting of security standards and the social distribution of costs and benefits, as well as their compatibility with ethical standards, are not just of a technical or scientific character, but have to be dealt with politically as well (Wynne 2001). This is taken into account by the trend of including a range of interests and moral values in science and technology governance processes by engaging representatives of the general public.

The expected benefits of public engagement are easier and faster decisionmaking by preventing public discontent, greater trust in decision-makers and in decisions reached through open and fair procedures, and enhanced knowledge of complex issues among decision-makers and citizens through the inclusion of lay knowledge and values as well as through mutual learning.

The ways in which citizens are becoming involved differ from country to country, depending on cultural and institutional structures - the civic epistemology of a country (Jasanoff 2005). This chapter will take a close look at public engagement in European countries, China and India. There are huge differences among the regions in economic development, political systems and levels of science and technology development. A comparison of these regions will help us better understand public engagement in science and technology governance.

\subsection{Public Engagement in Europe}

In Europe, forms and methodologies of public involvement have attracted increasing attention since the 1960s, in line with successive waves of societal democratization. The 1990s in particular, when the Soviet system disintegrated, marked a phase of transition and, to some extent, democratization for Europe. Concepts and theories of deliberative and participatory democracy gained importance in scientific and policy circles.

These developments coincided with the increasing emergence of critical debates on science and technology provoked by environmental, health, safety and food scandals, such as those relating to asbestos, contaminated blood reserves and the BSE ('mad cow disease') crisis. Thus the equating of technological progress with the amelioration of human living conditions was challenged, with scientific expertise becoming a politically contested field.

The failure of science, in the eyes of many members of the public, to speak truth to power in fields such as the environment, consumer protection and agriculture, as well as the strong opposition to genetically modified organisms in sections 
of the public, has led to reappraisals in the field of policy advice and to the establishment of technology assessment institutions in many European countries.

In the past 10-15 years, a series of documents and actions in Europe have marked a shift from the 'public understanding of science' paradigm to a new appreciation of citizens and their views on ethical problems, including risk management and legal and socioeconomic issues related to new technologies (Hennen 2013). A case in point is the call for dialogue, participation and empowerment of the European citizen in the European Commission white paper of 2001 on European governance (EC 2001a). A report by the white paper working group (EC 2001b) recommended that the selection of expertise used in the process of policymaking be revised, that guidelines be established for the selection of expertise, and that as broad as possible a spectrum of expertise be consulted in policy advice. Most prominent of the recommendations regarding socially robust knowledge for decision-making was the creation of 'greater opportunity for informed participation by society in policy-making'. The promotion of participatory procedures was one of the means to be employed to support 'public debate, knowledge-sharing and scrutiny of policy makers and experts' (EC 2001b: ii). The EC took up this reorientation of science and technology governance in its Science and Society Action Plan (EC 2001c). The action plan recommended involving people actively in technological development and giving them the 'opportunity to express their views in the appropriate bodies' (EC 2001c: 14). To this end participatory policymaking would have 'to be widened and deepened to systematically include other sectors of civil society at all stages' (EC 2001c: 14).

Participatory technology assessment (pTA) is one of the most important exercises for promoting public engagement in science and technology governance (Decker and Ladikas 2004). Some standard participatory methods have been developed in the course of such exercises-such as citizen juries, consensus conferences, 21st century meetings, charrettes, focus groups, deliberative polling, scenario building exercises and technology festivals-as well as new and experimental forms that mostly recombine the standard methods. The following analysis will describe a case study of technology assessment practices with lay participation in genetically modified food technology.

\subsubsection{PTA Practices in the Governance of Genetically Modified Foods in Europe}

The shift to the predominance of the science and society paradigm in Europe corresponds with several events related to food and agriculture, such as the BSE crisis, the birth of the cloned sheep Dolly, the arrival of genetically modified corn and soybeans from the United States and the trade conflict between the US and Europe resulting from Europe's ban on hormone-raised beef (Ansell et al. 2006: 97). In this context, decision-makers realized that governmental food safety policies could easily provoke high politicization and public distrust. 
Genetic modification in food production provokes concerns about health and safety issues and raises ethical and moral objections. For example, the consumption of genetically modified food would be ethically problematic, in an indirect way, if its production caused or risked harm, violated rights or caused injustice. Genetically modified foods also provoke other reactions: some perceive them as 'unnatural' and as a violation of the intrinsic value of nature. Thus, when nature or the environment is thought of as an object of ethical concern, regardless of how the environment affects the interests of humans, genetically modified foods raise ethical issues about the rights and wrongs of the ways humankind affects nature that are particularly difficult to explore and resolve. Surveys show that there is a gap between the favourable public perception of biomedical applications and the negative perception of agri-food biotechnology, although there are significant differences among European countries. This is in line with the observation that over the past two decades heated debates have taken place in many European countries between decision-makers, experts and stakeholders, including lay people as consumers, about genetically modified plants and foods without common ground having been found between proponents and opponents.

One could add here that in several EU member states, such as France, the United Kingdom and Germany, public engagement started with self-organized activism on the part of citizens who destroyed genetically modified test crops or occupied supermarkets that were selling genetically modified products. In particular, countries that had not used pTA beforehand tried to introduce it to appease activists and the broader public. This was the case in France, the UK, Germany and Austria. In countries including Norway, Denmark, Switzerland and the Netherlands (all relatively small, with fewer than ten million inhabitants), forms of pTA or other forms of political participation had already been established, and the genetic modification debate did not become as intense as in the other countries.

Based on documents available on the internet and scientific literature on pTA published since the 1990s, we have identified 20 pTA exercises in the field of genetically modified foods, 15 of which involve lay people. These can be subdivided into eight consensus conferences, three focus groups, one charrette, two 21 st century town meetings, one scenario building exercise, and one event in a science museum that cannot be categorized. The UK's 'consumer views on genetically modified food' combined focus groups, a local citizens jury and events for students, but we have listed it as a focus group exercise because the exercise consisted mainly of focus groups. Of the 15 lay pTA exercises, 13 were organized by specialized technology assessment bodies or state institutions, one by a research organization that had no direct link to a national parliament or government (Citizen GMO UK) and one by a science museum (Future Foods (UK)).

The common objectives of almost all of these pTA practices comprised the improvement of information about genetically modified organisms, the stimulation of a broad public discourse based on a higher quality level, and the facilitation of dialogue between experts and non-experts. Some organizing bodies additionally mentioned that they wanted to test or improve methodologies of discursive practice.

Regarding the impacts of the analyzed practices, the picture is mixed. Nearly all practices ended with written reports, but for many of them, the trail of political 
impact got lost after the written report and some press coverage, especially in France, the UK and Germany. Other procedures, however, seemed to have a closer link with political institutions. TA-SWISS, for example, was able to present the results of a citizen conference, or 'PubliForum', on genetically modified food to the parliamentary commission for science, education and culture. The Danish Board of Technology stated that political interest in the field of genetically modified food had increased in the wake of a consensus conference held on the issue, and that both national and EU politicians had shown interest in the project, with a view to becoming better informed about citizens' perspectives. In the end, however, the interest shown may not have been sufficient to modify policies or regulatory principles (Hansen 2006). In Norway there was the special case of two consecutive consensus conferences within 4 years with the same lay panel. Both enjoyed high mass media coverage, and the conference facilitators were invited to present the major conclusions and recommendations in the Norwegian parliament.

What is the lay people's opinion on genetically modified food, as far as it can be summarized from these activities? While the proponents of genetically modified plants highlight the environmental and economic benefits (fewer fertilizers, fewer pesticides, less tillage, higher productivity), the opponents put more emphasis on health and environmental risks, as well as factors such as naturalness and the integrity of nature. Furthermore, many consumers have difficulty identifying clear benefits of genetically modified food products. Some consumers would be willing to spend more money on genetically modified products if they provided a better taste or a higher nutritional value.

Concerning the governance of science and technology in the field of genetically modified food, French and UK citizens in particular complained that public debate had come too late. Their suspicion focused on the government having made a decision already, with inadequate knowledge of citizens' needs, and on the motivation of multinational companies to promote their own interests above the wider public interest. Many lay people felt that very little information was available to the public on genetic modification: they needed to know more about what genetic modification was, what safety tests had been done, and about the regulating bodies and their responsibilities. Many citizens expressed concern about the power multinational companies exerted through the patenting of seeds-power that might affect the social distribution of costs and benefits. Consequently new regulations that were fair to primary producers, developers and end users were recommended. Another big topic for almost all citizens was openness and transparency. Consumers wanted clear and effective labelling and tracing that allowed them to make an informed choice between food that was genetically modified and food that was not.

With regard to risk and regulation, many lay people were worried about the possible impacts of genetic modification on the environment and biodiversity. They were therefore in favour of more precaution and argued that more time was needed to understand the long-term implications of genetically modified crops before farmers started growing them.

What the analyzed pTA practices have in common are concerns about the non-excludability of specific risks in the context of today's level of scientific 
knowledge-for example, the theoretical risk of antibiotic resistance being transferred to human beings. There are calls for intensified independent public research, combined with strong ethical guidelines.

Most lay recommendations include calls for greater consideration of ethical aspects in genetically modified research, for example via a code of practice or the establishment of a council on gene ethics, to ensure a continuing ethical debate in society. There is particular concern about the genetic modification of animals, as well as the crossing of barriers between animals and plants. In this context the Danish lay panel stated that ethical considerations of interference with individual plants or animals should be seen in an overall framework, taking into account the whole of living nature and its integrity.

\subsubsection{Conclusions}

In Europe, the search for new forms of governance of science and technology is ongoing, and part of it is about a redefinition of the role of experts, stakeholders and lay people in policy-making. The science and society paradigm now sees everyday aspects of life, previously deemed apolitical, as politically relevant. Given the increased frequency and widespread use of participatory procedures in technology assessment, it can be said that pTA and public engagement in science and technology policy-making are widely established practices in Europe.

To date, however, there has been little systematic empirical evaluation of the role and impact of pTA processes (Hennen 2013). Some reports clearly show that lay people are able to discuss highly complex societal and ethical aspects of science and technology reasonably and can engage in dialogue with experts, and that formats such as consensus conferences are suitable for initiating cooperative learning processes among lay people. There are thus indications that deliberation-in the sense of joint reasoning on societal problems - can be achieved in pTA processes.

Studies indicate that the resonance of pTA in the media and in policy-making is often quite restricted (Joss and Bellucci 2002). Analysis of the factors conducive or obstructive to the public and political resonance of pTA arrangements (Hennen 2002) suggests that the potential influence of pTA is affected by the quality of the outcome of a pTA process or by features of the procedure itself (management, actors involved). More important than features of the procedure, however, is the context in which the procedure takes place. The nature of the issue or problem at stake and the institutional and political setting of the pTA arrangement appear to be of the greatest importance.

\subsection{Public Engagement in China}

Before reforms and opening up started in China in 1978, the state-led science and technology system was a highly hierarchical one in which public participation was rare. In the past 30 years, the Chinese government has taken active measures to 
involve more parties, including the public, in science and technology governance. The Law of the People's Republic of China on Science and Technology Progress, as amended in 2008, explicitly provides for the rights of the public to participate in decision-making on science and technology affairs: 'The State encourages government departments, enterprises, institutions, public organizations and citizens to participate in and support activities for progress of science and technology' (China 2008).

This encouragement of public participation in the formulation of the country's science and technology policies was reflected, for example, in the compilation of the Outline of the National Program for Long- and Medium-Term Scientific and Technological Development. In 2003, the Chinese government had begun to design multiple forms of public participation in accordance with the principle of 'public participation, brainstorming, democratic decision-making and scientific decision-making'. The Ministry of Science and Technology, for example, opened a new channel about the outline on its official website to keep the public informed of progress, and launched a public participation forum with 19 topics that the public could visit to make comments and share views on the compilation of the outline. These measures strengthened communication and interaction with the public. Later, in the review and evaluation of the implementation of the outline, the office in charge of the programme issued more than 2,000 questionnaires and organized more than 100 working meetings to solicit expert opinions from relevant government departments, enterprises, higher-learning institutions, research institutes and industry associations ( $\mathrm{Li} 2011$ ).

Meanwhile, as the rapid economic growth of the past 30 years has greatly improved Chinese people's living conditions and levels of education, the Chinese public's awareness of rights and perception of risks have risen accordingly. As a result, the Chinese people are more willing and able to participate in the governance of science and technology.

The case of the protests against PX projects in China is a good illustration of this tendency. PX is the abbreviated name for the dangerous chemical p-Xylene, which is strongly carcinogenic and teratogenic. In 2007, a petition cosigned by six members of the Chinese Academy of Sciences and 100 members of the Chinese People's Political Consultative Congress was submitted to the congress against the plan to establish a PX plant in Xiamen city, Fujian province. This proposition was reported in the media and received extensive public attention. Local people debated furiously in online forums and took to the streets holding banners bearing words such as 'I love Xiamen' and 'We oppose PX'. However, the city government did not pay enough attention to the protest. On the contrary, the government accelerated the project while taking control measures such as confiscating magazines, closing websites and blocking SMS messages. These measures only fuelled the circulation of the PX information among local residents, who planned a street 'stroll' against the PX project via SMS. In early June, some residents wearing yellow ribbons launched a 'stroll' in front of the seat of the city's government, bringing public participation in the matter to a head (Song and Yu 2012). It was only then that the government took account of the public's demands and responded 
positively. After that, the government made active efforts to listen extensively to the opinions of residents through a variety of channels such as SMS, telephone, fax, email and mail. In December 2007, the Xiamen government formally issued an environmental assessment report on the PX project and convened a symposium. Eventually it was decided, on 9 January 2009, that the PX project would be moved to another city.

From this case and many others, it is possible to identify some general characteristics of public engagement in China. First, the main public participants in science and technology governance include direct stakeholders, indirect stakeholders, social groups, lay experts and the general public. There is a lack of independent third-party social groups, especially in large-scale campaigns, in which independent NGOs are not allowed to participate. It is the absence of independent organizations that has led to the occasion-specificity and disorderliness of public participation.

Second, the direct cause of public participation in science and technology governance is their shared stake. Why did the Xiamen PX incident provoke a strong public response? The answer is that it was localized, it touched the vital interests of local residents, and it was caused by the omission of local government from the process. When the local public have shared motivations and common interests, they are better positioned to launch a large-scale mass campaign as a means of public participation.

Third, public participation in science and technology governance is mainly bottom-up and post-occurrence, and lacks formal channels. Many important incidents of public participation have taken place after, rather than before, the occurrence of the problems. They have mostly taken the form of bottom-up campaigns to exert pressure on the authorities, which in some cases respond by setting up formal consultative and participatory processes. Just as some scholars have observed, public participation in the decision-making on science and technology affairs is mostly spontaneous and non-institutionalized and lacks legal protection, and is also often ignored by decision-makers (Fan et al. 2011).

\subsection{Public Engagement in India}

Four pillars underlie India's science and technology goals: techno-nationalism, inclusive growth, techno-globalism, and global leadership (Mashelkar 2008). The Science, Technology and Innovation Policy 2013 issued by the Ministry of Science and Technology observed that science and technology systems had to undergo a paradigm shift from the current input-driven innovation model to a more development-led strategy. The document emphasized the importance of public awareness of Indian science and technology. It stated that "public and political understanding of science should be based on evidence and debates with open mind. People and decision makers must be made aware of the implications of emerging technologies, including the ethical, social and economic dimensions'. 
India has a vibrant civil society, but in science and technology issues that civil society has much more potential to contribute. To begin with, not many groups are active in science and technology policy or in promoting pTA in India, and those that are there work on issues like sustainable agriculture, traditional medicine and the rights of forest dwellers, with a focus on praxis rather than on policy aspects. In the controversy over Bt brinjal, many of these groups came together and opposed the granting of permission for the commercial cultivation of the plant, but the same level of involvement is missing from the debate on policy issues like the proposed Biotechnology Regulatory Authority of India Bill. Although civil society groups opposed the bill, which proposed replacing the current regulatory system with a new regulatory authority, the debate was not as intense as the controversy over Bt brinjal.

There are not many civil society groups working on science and technology policy issues in India. One reason, perhaps, is that not many universities or institutions of higher learning offer courses in science and technology policy or studies. Another factor could be that science and technology policy is too diffuse a topic to attract NGOs that usually focus on a single sector, such as health, agriculture or workers' rights. Some groups are working on nuclear energy and atomic energy issues, but are divided on nuclear energy for peaceful uses.

There are some think tanks and other initiatives that have links with academic institutions working on science and technology policy issues, broadly speaking, but these are not activist groups. They can, however, be considered part of civil society. For example, the Knowledge in Civil Society Forum is a network of academic institutions, researchers and NGOs working on agriculture, knowledge and innovation. As part of the SET-DEV (Science, Ethics and Technological Responsibility in Developing and Emerging Countries) project funded by the European Commission, the forum published Knowledge Swaraj: An Indian Manifesto on Science and Technology in 2011. Earlier it held a national workshop with civil society groups engaged in science and technology issues. A perusal of the papers and proceedings indicates that the groups working on irrigation, energy, sustainable agriculture and forestry, and researchers working on traditional medicine, innovation studies, and agricultural research and extension, participated in the workshop. However, although they covered many issues, there was no focus on science and technology policy or policy making per se.

Participation is an important issue in India, however. There are groups that work on participatory rural appraisal, irrigation, the participatory auditing of projects and the participation of marginalized groups in civic bodies. But their focus on participation is more on empowerment issues than on assessing systems and technologies. As in the case of science and technology policy, it is also difficult with pTA to identify any group or organization that is focusing on this, although there are many groups promoting alternative technologies in different sectors. One reason is that technology assessment itself is not a well-developed or thoroughly researched topic in India. The Technology Information, Forecasting and Assessment Council is an agency under the Department of Science and Technology that performs technology assessment, but pTA is a new concept in India and not much work has been done on it. 
The major constraint is the fact that civil society groups are not involved in science and technology policy issues and lack expertise in technology assessment. Environmental groups, trades unions and people's science groups are quite active in defending people's rights and interests with regard to technological change, among other areas, and aspects of technology assessment play a role in relation to these activities, but technology assessment as a methodology is perceived as a matter for researchers. There is enough scope for pTA in India, particularly in the case of biotechnology, agricultural technologies and energy technologies. Participatory rural appraisal and the participatory management of natural resources in joint forest management have been thoroughly tested in India. The challenge lies in translating the need into action. What is required is interaction between civil society, policy-making and research to strengthen public participation in interdisciplinary problem-oriented research.

\subsection{Discussion and Conclusion}

It can be concluded from the research on pTA and its political role that the chances of public engagement being visible in public or political debates are relatively good when the political situation is open, with interested parties looking for new ways to solve problems and no immediate decisions at stake. Typically these are situations in which the problem has not yet been well defined politically or in which the interested parties are searching for common paradigms to solve the problem. The results of public engagement arrangements have a good chance of being referred to in the public sphere and in policy-making if the focus is on the development of ideas and the objectives are not highly contested. When the issue at stake is highly contested and interest groups hold definite positions on it, public debate of the benefits and risks may still continue, but it is highly unlikely that independent policy advice or consultation will have any kind of impact, regardless of whether it is expert or participatory (On this and the following, see Hennen 2013).

The unclear political status of public engagement and the fact that it often appears to have little influence on decision-making have, taking pTA as an example, led to criticism (Rayner 2003; Stirling 2007; Abels 2007; Bora and Hausendorfer 2006). Although such criticism is justified with regard to many individual pTA exercises, the conclusions drawn from observation of the limited effect of pTA seem unduly strong. The effect is limited because there is no defined role for pTA in the established decision-making processes, not through any inherent bias against pTA procedures. It can be demonstrated that the outcomes of many pTA procedures (i.e. their conclusions and recommendations) contradict the expectations held by experts and decision-makers. The argument that pTA is a way of framing issues that allows non-scientific arguments (considered to be irrational) to be ruled out by the process, or that it involves citizens in a procedure that rules out their authentic attitudes, does not find much support in empirical studies 
of the outcomes of citizen juries in contested fields of technology or scientific development.

Framing and the instrumental use of outcomes are, as Stirling (2007) has argued, a problem for any type of policy advice and technology appraisal. He holds that participatory appraisal is as open to power and justification strategies as is expert appraisal. PTA can be used to induce 'technical commitments', that is, a closure of processes of technology development, instead of opening them up for new perspectives and values.

However, it is by providing for transparency and by giving as much control of the process as possible to participants that practitioners strive for an open and unbiased process. In brief, there are rules of good practice, some of them derived from Habermasian discourse ethics, that can protect against instrumental use and framing. With regard to expert appraisal (science), one cannot deny the relevance of central institutional features of science such as peer review and methodological scepticism, despite known cases of scientific fraud. Similarly, participatory appraisal is guided by discourse rules and the principle of transparency, which are functional equivalents to the Mertonian principles of science.

An evaluation of the effects of pTA must take into account that it is quite difficult, and often impossible, to identify the effects of scientific advice on decisionmaking processes. Such processes are generally influenced by a complex set of interests and rationalities (Albaek 1995). Thus expert appraisal often suffers from the same lack of visible impact as participatory appraisal. In contrast to expert appraisal, however, pTA cannot simply be regarded as a paid service to policymaking that may be heeded or not. Because it includes underrepresented societal perspectives, pTA carries a connotation of democratizing science and technology policy and produces expectations of democratic inclusion. A lack of perceivable impact is therefore more problematical for pTA than for expert appraisal and might, in the long run, create grave disappointments.

For our comparison among the three regions of the state of the art in public participation, it is worth noting that civil society in European countries has been fighting for more participation in local, environmental, and technological decisionmaking since the 1960s. In Germany, for example, the Planungszelle, a kind of citizen jury, was developed in the 1970s to handle local environmental conflicts. Concerning participation in technology policy, it took over 20 years, particularly in the bigger European countries, for methods like the citizen jury to be transferred to the field of technology policy.

This evolution in Europe has been advanced by different developments, including the waves of democratization since the 1960s, the rise of environmental activism and civil society organizations since the 1970s and 1980s, and the publicly perceived accumulation of governance failures or scandals in the 1990s.

The Chinese PX case shows some parallels to European environmental activism and disputes in the 1970s and 1980s, when environmental NGOs and parties evolved. But, of course, these developments took place in different sociocultural settings. The Chinese government is starting to emphasize the importance of social engagement in science and technology governance. Meanwhile, the Chinese 
public are more willing and able to participate. In future, the more difficult work is going to be building up a better institutional environment for public engagement in China.

In India, there is already a certain sentiment for self-organized bottom-up engagement and empowerment of local civil society groups and NGOs acting in specific local and cultural or application-oriented contexts. However, these groups and organizations still face problems in reaching or addressing science policy actors because they often lack the technical capacity to address broader and overarching science and technology issues beyond their operational context, and they also lack channels to the policy-making levels.

Europe, on the other hand, has to some extent managed to channelize, and even forestall, activist movements by offering alternative different channels for more or less extensive participation by stakeholders and the general public. In addition, science and technology governance in Europe could profit from a range of context-specific knowledge leading to more robust technology implementation processes.

Open Access This chapter is distributed under the terms of the Creative Commons Attribution Noncommercial License, which permits any noncommercial use, distribution, and reproduction in any medium, provided the original author(s) and source are credited.

\section{References}

Abels G (2007) Citizen involvement in policy making: does it improve democratic legitimacy and accountability? The case of pTA. Interdisc Inf Sci 13(1):103-107

Albaek E (1995) Between knowledge and power. Utilisation of science in public policy making. Policy Sci 28:79-100

Ansell C, Maxwell R, Sicurelli D (2006) Protesting food: NGOs and political mobilization in Europe. In: Ansell C (ed) What's the beef?. MIT Press, Boston, The contested governance of European food safety, pp 97-122

Bora A, Hausendorfer H (2006) Participatory science governance revisited: normative expectations versus empirical evidence. Sci Public Policy 33(7):478-488

China (2008) Law of the People's Republic of China on science and technology progress. Ministry of Science and Technology. http://www.most.gov.cn/fggw/fl/200801/t20080108_ 58302.htm. Accessed 4 July 2014

Decker M, Ladikas M (eds) (2004) Bridges between science, technology and policy: technology assessment-methods and impacts. Springer, Berlin

EC (2001a) European governance: a white paper. COM (2001) 428 final, European Commission, Brussels

EC (2001b) Democratising expertise and establishing scientific reference systems. Report of the working group on the white paper on governance, European Commission, Brussels, May 2001

EC (2001c) Science and society: action plan. COM (2001) 714 final, European Commission, Brussels

Fan C et al (2011) Public participation in science and technology decision-making in the 12th five-year period: needs and measures. China Soft Sci 6

Fiorino DJ (1990) Citizen participation and environmental risk: a survey of institutional mechanisms. Sci Technol Human Values 15(2):226-243 
Hansen J (2006) Operationalising the public in participatory technology assessment: a framework for comparison applied to three cases. Sci Public Policy 33(8):571-584

Hennen L (2002) Impacts of participatory technology assessment on its social environment. In: Joss S, Bellucci S (eds) Participatory technology assessment: European perspectives. University of Westminster, London, pp 257-275

Hennen L (2013) Parliamentary technology assessment in Europe and the role of public participation. In: O’Doherty K, Einsiedel E (eds) Public engagement and emerging technologies. UBC Press, Vancouver, pp 27-44

Jasanoff S (2005) Designs on nature: science and democracy in Europe and the United States. Princeton University Press, Princeton

Joss S, Bellucci S (eds) (2002) Participatory technology assessment: European perspectives. University of Westminster, London

Li C (2011) The recommendation of promoting public engagement in science and technology policy making. Internal report of Chinese Academy of Science and Technology for Development, No. 16, Beijing

Mashelkar RA (2008) Indian science, technology, and society: the changing landscape. Technol Soc 30(3):299-308

National Research Council (1996) Understanding risk: informing decisions in a democratic society. National Academy Press, Washington DC

Rayner S (2003) Democracy in the age of assessment: reflections on the roles of expertise and democracy in public-sector decision making. Sci Public Policy 30(3):163-170

Song Y, Yu W (2012) Exploring the reason for non-institutional political participation: an example from Xiamen PX. J Beijing Univ Technol (Soc Sci Ed) 12(1)

Stirling A (2007) 'Opening up' and 'closing down': power, participation, and pluralism in the social appraisal of technology. Sci Technol Human Values 33(2):262-294

Wynne B (2001) Creating public alienation: expert cultures of risk and ethics on GMOs. Sci Cult 10(4):445-481 